\title{
Tinjauan Etik Penentuan dan Pola Koordinasi Dokter Penanggungjawab Pelayanan (DPJP) pada Layanan Medis Multidisiplin
}

Pukovisa Prawiroharjo ${ }^{\mathrm{I}, 2}$, Anna Rozaliyani ${ }^{\mathrm{I}, 3}$, Ghina Faradisa Hatta, Mohammad Baharuddin ${ }^{\mathrm{I}}$

${ }^{\mathrm{I}}$ Majelis Kehormatan Etik Kedokteran Pengurus Besar Ikatan Dokter Indonesia ${ }^{2}$ Departemen Neurologi Fakultas Kedokteran Universitas Indonesia/Rumah Sakit Cipto Mangunkusumo ${ }^{3}$ Departemen Parasitologi Fakultas Kedokteran Universitas Indonesia

\author{
Kata Kunci \\ Etika, layanan multidisiplin, pola \\ koordinasi \\ Korespondensi \\ anna.rozaliyani@ui.ac.id \\ Publikasi \\ (C) $2020 \mathrm{JEKI} / \mathrm{ilmiah.id}$ \\ DOI \\ Io.2688o/jeki.v4iI.42 \\ Tanggal masuk: 2I November 2019 \\ Tanggal ditelaah: I2 Januari 2020 \\ Tanggal diterima: 1o Februari 2020 \\ Tanggal publikasi: 24 Februari 2020
}

\begin{abstract}
Abstrak Perawatan pasien yang melibatkan banyak disiplin ilmu dan perjumpaan dokter-pasien yang terpisah-pisah berpotensi menimbulkan perbedaan pendekatan dan rekomendasi antardokter. Kondisi ini dapat menyebabkan kebingungan pasien dan tumpang tindih dalam tatalaksana pasien. Prinsip layanan medis mencakup patient-centered care dan layanan berkesinambungan (continuity of care). Ketimpangan prinsip etik dapat dijumpai dalam layanan medis multidisiplin meliputi prinsip etik beneficence, nonmaleficence, autonomy, dan justice Tulisan ini bertujuan untuk mengingatkan kembali tujuan dasar pelayanan medis multidisiplin, serta potensi ketimpangan dalam praktiknya.
\end{abstract}

\begin{abstract}
Patient care involving multidisciplinary approach and its disjunct meetings toward patients potentially create a disparity in approach and treatment recommendation between attending physicians. This can cause confusion and overlapping recommended treatment. Patient-centred care and continuity of care are some of the important principles of medical care. Detriments in ethical principles are present while trying to establish those principles, including beneficence, non-maleficence, autonomy, and justice. This review aims at reviewing the basic purpose of multidisciplinary medical care, and any discrepancies in its practice.
\end{abstract}

Kondisi medis yang kompleks tak jarang membuat pasien memerlukan analisis layanan multidisiplin spesialistik bahkan subspesialistik. Kondisi itu mengharuskan pasien datang ke rumah sakit untuk menjumpai tim dokter yang terdiri dari berbagai spesialis dan subspesialis. Bentuk perjumpaan tersering yang dialami pasien di Indonesia, baik dalam konteks rawat jalan maupun rawat inap, adalah perjumpaan secara terpisah dan bukan dalam satu kesatuan perjumpaan yang diharapkan berujung pada kesatuan sikap dan rekomendasi atas kondisi medis pasien.

\section{Tanggungjawab Rumah Sakit dalam Menyelenggarakan Layanan Multidisiplin}

Peran rumah sakit sebagai suatu organisasi dalam menyelaraskan asas beneficence (asas manfaat atau kepentingan pasien di atas masalah lain) dapat tercermin pada beberapa peraturan. Rumah sakit berperan dalam pemeliharaan dan peningkatan kesehatan perorangan melalui pelayanan kesehatan paripurna tingkat kedua dan ketiga sesuai kebutuhan medis. Hal ini sesuai dengan Pasal 5 Undang-Undang Republik Indonesia Nomor 44 Tahun 2009 tentang Rumah Sakit. ${ }^{1}$ Pada peraturan tersebut juga disebutkan bahwa rumah sakit wajib menerapkan Standar Keselamatan Pasien (Pasal 43 UU Nomor 44 Tahun 2009) serta menyusun dan melaksanakan peraturan internal rumah sakit agar terwujud tata kelola perusahaan dan klinis yang baik (Pasal 29 UU Nomor 44 Tahun 2009).1,2 Dalam pasal 3 UU Nomor 29 Tahun 2004 tentang Praktik Kedokteran disebutkan bahwa pengaturan praktik kedokteran 
dilakukan agar tercapai perlindungan kepada pasien, peningkatan mutu pelayanan medis, serta pemberian kepastian hukum kepada masyarakat, dokter, dan dokter gigi. ${ }^{2}$

Mengacu pada undang-undang tersebut, perlu diterapkan koordinasi layanan multidisiplin. Pelayanan medis dewasa ini semakin berorientasi pada pendekatan patientcentered care dan kesinambungan pelayanan (continuity of care). ${ }^{3-7}$ Pendekatan tersebut diupayakan melalui layanan multidisiplin untuk memberikan manfaat yang seluas-luasnya kepada pasien.

\section{Kaidah Manfaat (Beneficence) terkait Pola Koordinasi Layanan Multidisiplin}

Perawatan pasien pada prinsipnya harus dilakukan dengan mempertimbangkan memberikan manfaat terbaik bagi pasien (beneficence). Perawatan pasien multidisiplin memiliki potensi menghadirkan aspek manfaat yang besar. Hadirnya dokter-dokter dengan kemampuan analisis mendalam dan beragam terkait kondisi medis pasien akan mampu menghadirkan penilaian yang detil dan komprehensif, yang akan membantu kesembuhan pasien. Kehadiran tim dokter juga dapat saling mengisi sehingga akan menutup banyak celah masalah medis yang tidak teridentifikasi.

\section{Kaidah Non-Maleficence dan Potensi Masalah dalam Layanan Multidisiplin}

Layanan multidisiplin dilaksanakan dengan susunan tim medis yang terdiri atas ketua tim (DPJP utama) dan anggota tim (DPJP terkait masalah medis pasien lainnya). Pada umumnya, pertemuan pasien dengan setiap DPJP terjadi dalam waktu yang terpisah-pisah. Perjumpaan yang terpisah-pisah ini berpotensi menyebabkan munculnya perbedaan sikap dan rekomendasi antardokter yang melayani pasien. Kebingungan atau tumpang tindih tatalaksana yang direkomendasikan dapat merugikan pasien sehingga perlu dicegah sesuai kaidah non-maleficence (menghindari timbulnya bahaya, kerugian, atau hal yang tak menguntungkan pasien).
Para dokter hendaknya menyadari bahwa prinsip dasar yang harus diutamakan adalah keselamatan pasien dan layanan medis terbaik untuk pasien. Untuk itu setiap dokter harus memberikan kemampuan terbaik berdasarkan kompetensi ilmu masing-masing, sekaligus berbesar hati untuk menyadari keterbatasan yang dimilikinya. Dengan demikian, tim dokter harus saling membantu sekaligus memberikan kepercayaan kepada anggota tim yang memiliki kompetensi ilmu paling memadai, sesuai dengan kewenangan klinis yang berlaku.

Perbedaan sikap dan rekomendasi interdisiplin dapat berkaitan dengan prinsip mendasar dalam memberi pelayanan kepada pasien, yaitu visi pendekatan layanan medis bagi pasien. Hal ini dapat dilihat pada layanan multidisiplin bagi pasien dengan kondisi penyakit terminal. Di satu sisi, terdapat klinisi yang masih bersikeras menggunakan pendekatan heroikpositivistik, yang mengejar dan menargetkan tercapainya parameter "perbaikan medis" berbasis pemeriksaan klinis, hasil laboratorium, atau radiologis. Namun, adapula klinisi yang lebih mengutamakan kualitas hidup pasien serta survival rate (kesintasan) dalam jangka waktu tertentu sehingga lebih memilih layanan paliatif. Pertimbangan ini didasari pemahaman kecilnya kemungkinan kesembuhan pasien atas dasar studi ilmiah. Sengkarut ini semakin kompleks ketika pasien atau keluarga yang dipandang layak membuat putusan juga terbelah sikapnya. Sengkarut ini tidak selesai bila para dokter yang menangani pasien tidak memiliki kesamaan pandangan dalam hal yang mendasar.

Potensi lainnya untuk melanggar kaidah non maleficence adalah tumpang tindihnya terapi medikamentosa. Koordinasi yang kurang baik pada aspek ini dapat menyebabkan pasien mendapatkan dua jenis obat yang memiliki golongan atau mekanisme kerja yang sama atau serupa dari dua orang dokter. Contoh lain adalah pemberian obat-obatan yang menimbulkan interaksi antarobat, yang dapat membahayakan pasien.

Potensi masalah lain adalah adanya miskoordinasi dalam merekomendasikan pemeriksaan penunjang. Hal ini dapat menyebabkan pasien mendapatkan 
pemeriksaan penunjang yang tidak diperlukan karena sebenarnya sudah direkomendasikan dokter lainnya. Misalnya, pada pasien trauma kepala CT-Scan kepala umumnya sudah pula memvisualisasikan kondisi mata dan hidung pasien sehingga pemeriksaan CT-Scan orbita secara terpisah sudah tidak diperlukan lagi.

Akar masalah tumpang tindih tersebut adalah koordinasi dan komunikasi yang tidak efektif antardokter, ${ }^{8-10}$ yang dapat berujung pada ketidakpuasan pasien, misdiagnosis, keterlambatan tatalaksana, kesalahan prosedur medis, bahkan kematian. ${ }^{11}$ Maka dari itu, standar koordinasi dan komunikasi antardokter harus dikembangkan serta difasilitasi pihak rumah sakit agar terlaksana dengan baik. Aspek koordinasi dan komunikasi antardokter ini juga tersirat diatur dalam pasal 7 dan pasal 9 Peraturan Menteri Kesehatan Republik Indonesia Nomor 1691 tahun 2011 tentang Keselamatan Pasien Rumah Sakit. ${ }^{3}$

\section{Ketimpangan Prinsip Etik Autonomy dalam Layanan Multidisiplin}

Prinsip etik autonomy (kewenangan pasien untuk menentukan pilihan atau membuat keputusan sendiri) pada praktiknya juga dapat mengalami ketimpangan. Contohnya, seorang pasien yang sebelumnya sudah sering berobat ke spesialis jantung A sehingga rasa percaya dan nyaman sudah terbentuk, masuk ke instalasi gawat darurat (IGD) atas indikasi stroke. Pasien tersebut memiliki lebih dari satu masalah kesehatan yang membutuhkan layanan multidisiplin. Berdasarkan masalah medis utama pasien, dokter spesialis saraf menjadi DPJP utama tim multidisiplin. Akan tetapi, pasien yang sadar akan autonomy-nya ingin memilih dokter spesialis jantung A sebagai DPJP utama, karena boleh jadi pasien belum memahami betul indikasi medis utama saat masuk ke IGD. Hal ini menimbulkan pertanyaan: berdasarkan prima facie, prinsip etik manakah yang harus diutamakan, apakah prinsip autonomy yang dijunjung oleh pasien atau beneficence yang mengutamakan kebaikan untuk pasien? Secara etis, klinisi harus menghormati hak autonomy pasien sehingga tepat untuk menerima pilihan pasien tersebut. Akan tetapi, hendaknya klinisi juga memberikan pandangan medis berbasis bukti sebagai pertimbangan terbaik bagi kondisi pasien. Lebih elok apabila kemudian spesialis jantung A secara rendah hati menyampaikan pertimbangan bahwa demi kebaikan pasien, spesialis saraf lebih tepat untuk menjadi DPJP utama pada kondisi stroke yang dialami pasien tersebut. Dengan mengedepankan prinsip beneficence, dokter spesialis jantung A hendaknya menenangkan pasien dan keluarga agar mempercayai dokter saraf tersebut, walaupun keputusan akhir tetap dipegang oleh pasien.

Ketidaksesuaian rekomendasi antar-DPJP juga dapat menyebabkan benturan etis dalam layanan medis apabila pasien memilih untuk mengikuti rekomendasi yang diberikan oleh DPJP terkait lainnya yang bukan DPJP utama. Hal seperti ini harus ditangani dengan bijak agar dapat mencegah timbulnya konflik antarDPJP. Komunikasi interdisiplin menjadi kunci dalam hal ini. ${ }^{8-11}$

Prinsip pelayanan yang patient-centred care harus menjadi pertimbangan utama dalam pemilihan DPJP utama pada layanan medis multidisiplin. DPJP utama dapat ditentukan berdasarkan indikasi medis, kompetensi spesialistik, kewenangan klinis, pertemuan pertama, kesepakatan internal antara DPJP terkait, pilihan pasien, serta tempat perawatan, seperti ruang rawat intensif. Dalam hal ini, pilihan pasien hanya merupakan satu dari berbagai indikasi pemilihan DPJP utama. ${ }^{4}$ Namun, perlu dipertanyakan kembali, apakah sebenarnya indikasi tersebut sudah dipertimbangkan dari awal asuhan? Patut juga dipertanyakan tentang pemberian informasi terkait DPJP utama kepada pasien. Apakah dokter sebagai komunikator, sesuai dengan area kompetensi ketiga Standar Kompetensi Dokter Indonesia 2012, ${ }^{18}$ sudah mengomunikasikan hal tersebut kepada pasien sejak awal?

Stewart $\mathrm{dkk}^{19}$ mengatakan bahwa layanan patient-centered care menjunjung tinggi prinsip etik autonomy. Hal yang penting dilakukan adalah mengupayakan titik temu agar pasien memiliki pengetahuaan yang memadai tentang masalah medisnya atau tentang penanganan terhadap dirinya. Tantangan berikutnya adalah belum jelasnya batas sejauh mana autonomy pasien dapat 
ditegakkan. Apabila pasien menggunakan hak autonomy secara tidak proporsional, padahal ia belum memiliki pengetahuan memadai terkait kondisi penyakit dan layanan medis terbaik, maka pasien dapat mengambil keputusan yang kurang tepat, sehingga bertentangan dengan prinsip etik lainnya, yaitu non-maleficence.

\section{Ketimpangan Prinsip Etik Justice dalam Layanan Multidisiplin}

Komunikasi dan koordinasi yang kurang efektif, selain berdampak pada prinsip nonmaleficence juga mempengaruhi prinsip justice (keadilan). Pemberian obat yang tumpang tindih tidak hanya dapat meningkatkan risiko timbulnya efek samping dan interaksi obat, melainkan juga berdampak pada biaya yang dikeluarkan pasien, baik biaya pribadi maupun penjamin (asuransi, BPJS, perusahaan, dan sebagainya).

Selain itu, diskrepansi pendapat akan rekomendasi juga dapat dilihat pada penentuan perawatan intensif atau perawatan biasa. Prinsip keadilan disini perlu ditelaah, mengingat setiap pasien memiliki hak untuk perawatan yang optimal. Hal ini berhubungan dengan penentuan prioritas ruang perawatan intensif, yakni keadilan bagi semua pasien sesuai dengan pertimbangan medis yang proporsional.

\section{Saran Pengaturan Koordinasi antar-DPJP di Rumah Sakit}

Penentuan koordinasi antardokter harus dipersiapkan dengan baik sejak pasien pertama kali masuk ke rumah sakit. Kemampuan dan peran dokter di IGD atau triage perlu dioptimalkan dalam menentukan konsultasi awal kepada dokter spesialis terkait. Peran untuk memilah konsultasi pasien tersebut harus berpedoman kepada kewenangan klinis dokter spesialis yang paling berkompeten. Sekali lagi, pertimbangan utama harus diletakkan pada prinsip keselamatan pasien dan layanan medis terbaik bagi pasien (patient-centred care). Pemilahan konsultasi spesialistik yang kurang tepat bukan hanya berdampak pada disharmoni komunikasi antardokter, tetapi juga berakibat terhadap tata laksana pasien yang kurang optimal, bahkan dapat berakibat fatal. Dalam hal ini RS harus menetapkan peraturan yang jelas dan konsisten terkait pembagian peran, tanggunggung, dan kewenangan klinis yang harus dilaksanakan oleh setiap dokter.

Seorang DPJP utama berperan penting dalam mengintegrasikan layanan medis bagi pasien. Dalam hal ini, komunikasi intensif dan efektif dalam tim sangat berperan. Agar dapat mewujudkan kesinambungan asuhan tanpa terputus (seamless continuity of care), disarankan untuk mengadakan rapat tim yang melibatkan seluruh DPJP terkait sesuai kebutuhan pasien dan pihak manajemen rumah sakit. Hal ini juga perlu didukung oleh pihak rumah sakit untuk menyediakan fasilitas agar komunikasi dan data tentang pasien dapat dihimpun dengan baik dan DPJP utama dapat mengoordinasikan pengelolaan layanan medis yang terbaik bagi pasien tersebut. ${ }^{4}$

Memang pada praktiknya apabila hal ini diaplikasikan kepada setiap pasien rawat inap masih sulit. Oleh karena itu, dapat dipikirkan untuk menerapkan strategi tersebut pada beberapa kasus prioritas dengan penanganan multidisiplin yang cukup kompleks, seperti pada kasus langka, onkologi, geriatri, ataupun penyakit kronik. ${ }^{12-15}$ Sebuah penelitian oleh Yeung, et al. (2016) menunjukkan dampak yang signifikan dari implementasi layanan medis multidisiplin yang terintegrasi pada penyakit kronik dan kasus langka. ${ }^{12}$ The Australian Government Department of Health merekomendasikan pertemuan koordinasi layanan medis multidisiplin pada penyakit kronik, misalnya asma, stroke, kanker, diabetes mellitus, penyakit kardiovaskular, bahkan penyakit musculoskeletal kronis. Pada beberapa kasus, kehadiran pasien dibutuhkan pula dalam pertemuan. Konferensi tersebut tidak harus tatap muka secara langsung, melainkan dapat melalui telepon, video, ataupun kombinasi. ${ }^{16}$

Idealnya, pertemuan tersebut dihadiri seluruh dokter yang memberikan layanan medis dan melibatkan pihak keluarga pasien. Apabila kondisi ideal ini sulit dipenuhi karena kesulitan mencocokkan waktu antar dokter yang memberikan layanan, maka dapat difasilitasi dengan pembicaraan menggunakan teknologi saat ini yang dapat dibuka lebih dari satu kamar 
diskusi.

\section{KESIMPULAN}

Pemilihan DPJP utama dapat ditentukan berdasarkan indikasi medis, kompetensi spesialistik dan kewenangan klinis, pertemuan pertama, kesepakatan internal antara DPJP terkait, pilihan pasien, ataupun jenis ruang perawatan. Pasien perlu mendapatkan informasi memadai terkait kondisi penyakit dan layanan medisnya, termasuk penentuan DPJP. Komunikasi dan informasi merupakan poin penting dalam standar keselamatan pasien. Perawatan pasien secara multidisiplin dapat memberikan manfaat yang besar kepada pasien. Dalam praktiknya, koordinasi dan komunikasi interdisiplin harus terjalin efektif dan intensif agar patient-centred care serta continuity of care dapat terwujudkan dan adanya pelanggaran etika kedokteran dapat dihindari.

\section{KONFLIK KEPENTINGAN}

Penulis tidak memiliki konflik kepentingan dalam penulisan artikel ini.

\section{REFERENSI}

1. Undang-Undang Republik Indonesia Nomor 44 Tahun 2009 Tentang Rumah Sakit

2. Undang-Undang Republik Indonesia Nomor 29 Tahun 2004 Tentang Praktik Kedokteran

3. Peraturan Menteri Kesehatan Republik Indonesia Nomor 1691 Tahun 2011 Tentang Keselamatan Pasien Rumah Sakit.

4. Lumenta NA, Atmodjo D, Luwiharsih, Amatyah M, Sutoto, et al. Panduan pelaksanaan dokter penanggung jawab pelayanan (DPJP). Edisi 1. Jakarta: Komisi Akreditasi Rumah Sakit; 2014.

5. World Health Organization. Continuity and coordination of care: a practice brief to support implementation on of the WHO Framework on integrated people-centred health services. Spain: WHO; 2018. Dapat diakses: https:// apps.who.int/iris/bitstream/hand le/10665/274628/9789241514033-eng. pdf?ua $=1$

6. Louw JM, Marcus TS, Hugo JFM. Patientor person-centred practice in medicine? - A review of concepts. Afr J Prim Health Care Fam Med. 2017;9(1):e1-e7. http://dx.doi. org/10.4102/phcfm.v9i1.1455

7. WHO. Human factors in patient safety review of topics and tools: report for methods and measures working group of WHO patient safety. WHO; 2009. Dapat diakses: http://www.who.int/patientsafety/ research/methods_measures/human_ factors/human_factors_review.pdf

8. Stewart, MA. Stuck in the middle: the impact of collaborative interprofessional communication on patient expectations. Shoulder \& Elbow. 2018;10(1):66-72. http://dx.doi. org/10.1177/1758573217735325.

9. De Vries-Erich, J, Reuchlin, K, de Maaijer, $\mathrm{P}$, van de Ridder, J. Identifying facilitators and barriers for implementation of interprofessional education: perspectives from medical educators in the Netherlands. J Interprof Care 2017; 31: 170-174.

10. Hellier C, Tully V, Forrest $S$, et al. Improving multidisciplinary communication at ward board rounds using video enhanced reflective practice. BMJ Open Quality 2015;4:u206968.w2801. http:// dx.doi.org/10.1136/bmjquality.u206968. w2801

11. Foronda, C, MacWilliams, B, McArthur, E. Interprofessional communication in healthcare: an integrative review. Nurse Educ Pract 2016; 19: 36-40.

12. Yeung CHT, Santesso N, Zeraatkar D, Wang A, Pai M, Sholzberg M, et al. Integrated multidisciplinary care for the management of chronic conditions in adults: an overview of reviews and an example of 
using indirect evidence to inform clinical practice recommendations in the field of rare diseases. Haemophilia, 2016;22 (Suppl. 3):41-50. http://dx.doi.org/10.1111/ hae.13010

13. Raine R, Wallace I, Nic a' Bhaird C, Xanthopoulou P, Lanceley A, Clarke $\mathrm{A}$, et al. Improving the effectiveness of multidisciplinary team meetings for patients with chronic diseases: a prospective observational study. Southampton: NIHR Journals Library; 2014. Dapat diakses: https://www.ncbi.nlm.nih.gov/ pubmed/25642498

14. Pillay B, Wootten AC, Crowe H, Corcoran N, Tran B, Bowden P, et al. The impact of multidisciplinary team meetings on patient assessment, management and outcomes in oncology settings: A systematic review of the literature. Cancer Treatment Reviews. 2016; 42:56-72. https://doi.org/10.1016/j. ctrv.2015.11.007

15. Brännström F, Bjerregaard JK, Winbladh A, Nilbert M, Revhaug A, Wagenius $\mathrm{G}$, et al. Multidisciplinary cancer conferences: A systematic review and development of practice standards. Acta Oncol. 2015;54(4):447-53. http://dx.doi.or g/10.3109/0284186X.2014.952387

16. Australian Government Department of Health. Chronic disease management: multidisciplinary case conference medicare items for GPs. 2013. Dapat diakses: https:// www1.health.gov.au/internet/main/ publishing.nsf/t/04BC88E9B6672B16C A257BF0001E3786/\$File/FS\%20-\%20 GP\%20Multidis\%20Case\%20Conf\%20 -\%20Provider\%20Info\%2031-10-13.pdf

17. Undang-Undang Republik Indonesia Nomor 36 Tahun 2009 tentang Kesehatan.

18. Konsil Kedokteran Indonesia. Standar Kompetensi Dokter Indonesia. Jakarta: KKI; 2012.
19. Stewart M, Brown JB, Weston WW, McWhinney IR, McWilliam CL, Freeman TR. Introduction In: Stewart M, editor. Patient-centered medicine: Transforming the clinical method. 3rd ed. London: Radcliffe, 2014; 426 p. 